\title{
EN SITUACIÓN DE FRONTERA. VARIEDADES LINGÜÍSTICAS Y EXTENSIÓN FUNCIONAL DEL ESPAÑOL Y EL PORTUGUÉS EN EL NORDESTE DE MISIONES
}

\section{In a border situation. Linguistic varieties and functional extension of Spanish and Portuguiese in the northeast of Misiones}

\author{
Leonardo Cerno* \\ UNM / CONICET - IESyH \\ leonardo_cerno@yahoo.com.ar
}

Palabras clave
español y portugués en
contacto;
portugués misionero;
portuñol;
acomodación
lingüística

\section{RESUMEN}

En este trabajo presentamos una descripción de variables sociolingüísticas vinculadas al repertorio y el uso del habla en una comunidad del nordeste de Misiones (Argentina), cuya situación de proximidad con Brasil determina formas estables de bilingüismo portugués-español. Se presentan elementos vinculados con el uso del repertorio pluridialectal y bilingüe, así como un modelo interpretativo basado en hechos observados de acomodación lingüística, exponiendo por un lado algunos significados sociales vinculados a los usos de las variedades, y por el otro la extensión funcional de las mismas en la comunidad fronteriza.

\section{Abstract}

Keywords

spanish and

portuguiese in contact;

misionero portuguiese;

portuñol;

linguistic

accommodation
In this paper we present a description of sociolinguistic variables linked to the repertoire and the use of speech in a community in the northeast of Misiones (Argentina), whose situation of proximity to Brazil determines stabe modes of Portuguese-Spanish bilingualism. Elements related to the use and distribution of the pluridialectal and bilingual repertoire are presented, as well as an interpretative model based on observed facts of linguistic accommodation, exposing on the one hand possible social meanings associated with the uses of the varieties, and on the other hand the functional extension of these varieties in the border community. 


\section{Introducción}

Misiones cuenta con al menos tres lenguas nativas: el guaraní, con dos variantes, el guaraní criollo y el guaraní étnico; el español, en la modalidad del nordeste argentino, cuya transformación ocurrió en parte por contacto con el guaraní criollo (Abadía de Quant, 1996); y el portugués, llegado a fines del siglo XIX por motivos de la migración desde el vecino Rio Grande do Sul. Estas son las tres lenguas más habladas en la provincia, como consecuencia de su situación geográfica y de su consolidación como unidad política desde la creación del Territorio Nacional de Misiones en 1881. Al español, portugués y guaraní se sumaron, además, lenguas de inmigración europea como el alemán, polaco y ucraniano, entre otras, cuyo ingreso a la región ocurrió en las primeras décadas del siglo XX. Con el paso del tiempo se consolidó una sociedad cuyo multilingüismo se expresa de manera más evidente a lo largo de las dos fronteras internacionales, con Paraguay al oeste y Brasil al este, y en las "colonias" rurales. Por su parte, el relato histórico, la literatura, el folklore provincial han hecho de esta diversidad lingüística un símbolo de identidad cultural (cf. Grünwald, 1977; Amable, 1975; Camblong, 2014). Con todo, el caso misionero no ha sido objeto de estudios sociolingüísticos exhaustivos. Al contrario que en los vecinos estados del sur de Brasil, que cuentan con una situación de contacto multilingüe bastante parecida y en donde el tema lleva décadas de investigación (cf. Altenhofen et al, 2011, 2016, 2018), la realidad sociolingüística de Misiones ha sido, después de los aportes pioneros de Gründwald y Amable, casi solamente trabajada desde métodos "semiótico-lingüísticos" y de análisis del discurso (Camblong, 2014; Daviña, 2003). Por otra parte existen diversas aproximaciones etnográficas e históricas sobre colectivos migratorios, pero estas raramente se concentran en la dimensión lingüística (Gallero y Krautstofl, 2009; Gallero, 2016). La lingüística comezó su trabajo sólo en los útlimos años, particularmente a partir de la actividad del investigador norteamericano John Lipski (2015, 2017a, 2017b, 2018). Otros aportes han seguido la dirección iniciada por él, centrada en el contacto entre español y portugués en el este de la provincia (Steffen, 2021; Cerno, 2019; Cerno, Gutiérrez Maté y Steffen, en prensa), y en parte se ha avanzado también en el conocimiento preliminar de los dialectos del alemán (Cerno, 2019; Putnam y Lipski, 2016). Pero más allá de estas contribuciones, el multilingüismo en Misiones consituye un tema que todavía debe ser investigado desde diferentes dimensiones y perspectivas.

El tema que nos ocupa aquí se limita a la pareja contactual español-portugués, cuya particularidad consiste en que concierne a dos lenguas nacionales y oficiales, que además poseen extensión y prestigo globales. Estas lenguas "se encuentran" en la frontera este del territorio misionero (y correntino), en el límite internacional entre Argentina y Brasil, hecho que si bien replica una situación más o menos típica a lo largo de la frontera de Brasil con sus vecinos hispanohablantes (Paraguay, Bolivia, Perú, Ecuador, Colombia y Venezuela), en Misiones (como en Uruguay) el contacto ocurre de una manera especial por contar con un número importante de hablantes nativos de portugués. Frente a esta realidad, nuestro objetivo consiste en describir la conducta lingüística de la población que habita en el espacio social de la región de frontera, en vistas a la comprensión de los factores contextuales que determinan el uso del español y el portugués, y de hecho, de sus diferentes variedades. La región de interés de nuestra investigación abarca tanto pueblos como ciudades pequeñas del este provincial, a lo largo de 200 km, desde San Javier hasta Comandante Andresito. Para la recolección y elaboración 
de los datos seleccionamos métodos cualitativos, que se adaptan a nuestras posibilidades de trabajo de campo y son adecuados para alcanzar al menos de manera provisional nuestro objetivo.

\section{Aspectos metodológicos}

En tal sentido nos incorporamos en una red social de una colonia periférica de la ciudad de San Antonio, Piñalito Norte, en el departamento de General Belgrano. Fundada en la década de los '60, Piñalito Norte recibió su mayor contingente poblacional después de 1980. Junto a campesinos misioneros, muchos de ellos con ascendencia alemana y alemana-brasileña, llegaron también numerosos migrantes de las regiones vecinas del Brasil, asentándose en situación de ilegalidad que poco a poco fue regularizada (cf. Schiavoni, 1998/1999; Gallero y Kraustofl, 2009). Según nuestras fuentes locales, unas 3500 personas habitan la colonia, incluyendo los alrededores. El trabajo de campo se dio en dos estadías de una semana cada una, y con corresidencia en la casa de nuestra informante facilitadora. Esto favoreció una situación de observación participante, cuya extensión abarca también los pueblos próximos de Comandante Andresito, San Antonio e Hipólito Irigoyen. En estas instancias realizamos entrevistas abiertas o no estructuradas con unas 45 personas, la mayoría residente en Piñalito. La situación de entrevista se enmarcó en el concepto de "visita” encabezada por nuestra informante facilitadora a diferentes vecinos de su red social. Esta red cubre varios sectores de la colonia (nuestra receptora fue una maestra de varias generaciones en Piñalito y es conocida en toda la zona). Las entrevistas no respondieron a un plan riguroso, las preguntas se hicieron en vistas a suscitar la asociación libre de anécdotas, recuerdos, evaluaciones y actitudes, con foco en los temas, intereses y categorías del pensamiento comunitario (categorías emic). La mayoría de los informantes fue entrevistada una sola vez y se esperan lograr entrevistas "en profundidad" en el corto plazo.

En esta presentación elaboramos los datos obtenidos en la segunda estadía del trabajo de campo, complementando así lo que ya publicamos al respecto (Cerno, 2019), y en cierto sentido extendiendo las preguntas hacia otros dominios de la relación entre sociedad y lengua. En el presente trabajo pretendemos dar una respuesta hipotética a la pregunta que dio carta de nacimiento a la sociología del lenguaje a fines de la década de los 50 y que es "quién habla a quién en qué lengua y con qué finalidad”. Es decir, nos centramos en el uso del repertorio de los hablantes bilingües, teniendo en cuenta el contexto y las implicancias sociales de los usos.

\section{Variedades lingüísticas y repertorios}

El portugués brasileño llegó a Misiones posiblemente antes que el castellano, traído por las tropas imperiales que se movilizaban en el sur del territorio actual en la marcha hacia los escenarios de la Guerra de la Triple Alianza (1865-1870). Finalizada la guerra llegaron, en la última década del siglo XIX, los migrantes del país luso que escapaban de los conflictos políticos del vecino estado de Rio Grande do Sul. Estos eran no solo cabloclos riograndenses sino también europeos de lengua alemana, sueca o rusa, que abandonaban el Brasil después de malas experiencias de migración y que 
probablemente ya hablaban portugués (cf. Altenhofen et al., 2018). El portugués que trajeron los diferentes grupos migrantes se daba en su variedad rural riograndense, diferente en varios aspectos del portugués padrão o estándar (trabaio vs. trabalbo, nós procuremo vs. nós procuramos). El portugués hablado actualmente en Misiones resulta de la extensión geográfica de este dialecto del portugués brasileño (Lipski, 2017, p. 401) y no debe confundirse con las variedades supraregionales del Brasil, con más prestigio y propias de la población escolarizada, de las situaciones formales y de los mass media. Hablado fuera de su comunidad nacional, el portugués misionero constituye "dialecto sin techo" (dachloser Dialekt, cf. Steffen, 2021, p. 134) y como tal acentúa sus rasgos deviantes con respecto al portugués padrão, así como recibe gran influencia de la lengua de la comunidad receptora. El castellano presta a este portugués sobre todo elementos léxicos (p.ej.olla vs. panela; mamá, papá vs. mãe, pai; lunes vs. segunda-feira). Se ha mostrado a su vez que la variedad ha sido poco afectada en su fonología y morfosintaxis por parte del español (Lipski, 2017a, 2018). Por su parte, el castellano misionero cuenta con una variante vernacular, que corresponde al habla de la franja del este provincial, con influencia del portugués en el léxico y en la sintaxis, y con otra más próxima al estándar, transmitida a la población escolarizada y que corresponde al "castellano general misionero" (p. ej. los chico va a la escuela vs. los chicos van a la escuela, no va a dar cierto vs. no va a salir bien, etc.). En la comunidad en estudio el contacto con el español estándar ocurre en la escolarización primaria y secundaria. E1 portugués padrão, que no se enseña en las escuelas (con excepciones), ${ }^{1}$ se difunde a su vez por medio de la radio y televisión brasileñas. Existe pues un acceso asimétrico a las dos variedades estándar, uno a través de la escolarización, y el otro a través de una participación más bien indirecta con la norma culta y la sociedad del país vecino.

A las variedades del castellano y portugués vernáculos debemos sumar las variantes habladas como lenguas segundas, es decir el español de los sectores con portugués como lengua primera, y el portugués hablado por sectores cuya lengua materna es el castellano. En ellas, a las interferencias más o menos frecuentes de la lengua de sustrato, se suma la mezcla ocasional de segmentos de español y de portugués, generando el fenómeno conocido como code mixing o mezcla de lenguas. Este hecho las lleva a distinguise de las variedades habladas como L1, tanto desde el punto de vista de su estabilidad variacional como por su valor como indexicador sociolingüístico. Es sin embargo el primer caso, el español L2 hablado por las familias de inmigrantes, el que merece aquí una atención especial. En efecto, este constituye un verdadero diastrato de migración y no un fenómeno vinculado al contacto ocasional, como es el caso del portugués hablado como L2. De hecho el alto índice poblacional de origen migrante (alemán-)brasileño en la región bajo estudio hacen de este español L2 la variedad quizás más usada en la comunidad. Por su parte, el portugués L2 constituye, como a lo largo de toda la frontera del Brasil con hispanoamérica, más bien un pidgin con función vehicular, siendo su aprendizaje asistemático e incompleto. Su uso responde sobre todo a las relaciones comerciales con vendedores o clientes brasileños. Su modelo es la norma padrão y no el portugués misionero.

1. En las comunidades investigadas existe una escuela en la modalidad "Escuela Intercultural Bilingüe de Frontera", donde los alumnos reciben clases de portugués estandar, ubicada en San Antonio. La modalidad existe desde 2005. 
Es cierto que en ambas variedades habladas como L2 se notan fenómenos muy parecidos de mezcla de lenguas (Lipski, 2015). Pero esta mezcla ocasional y situacional debe entenderse más bien como un hecho de habla, no de lengua, dependiente en parte de la capacidad del hablante en la lengua extranjera. Por otra parte, estudios recientes permiten sostener que los hablantes bilingües del portugués misionero y el español pueden diferenciar y mantener separadas ambas variedades (Lipski, 2017a, 2018). Así, no nos parece que convenga hablar de un "portuñol” en Misiones en tanto variedad mixta, diferente del portugués y el español vernáculos. ${ }^{2}$ Por el contrario, son estas dos variedades de contacto que, si bien reciben y transmiten elementos del léxico y sintaxis, y favorecen la práctica del code mixing, conservan también su distancia estructural (véase Steffen, 2021; Lipski, 2017a, 2018). Nos parece en este sentido que la mezcla del español y el portugués ("portuñol”) debería ser estudiada más bien como una modalidad dependiente del contexto antes que como una variedad criolla o mixed language.

Ubicamos en la Tabla 1 el continuo de variedades lingüísticas de la comunidad fronteriza del este de Misiones. En los extremos superiores se ubica la norma estándar de ambas lenguas, de alcance suprarregional, y hacia abajo las variedades vernáculas nativas, así como las derivadas del bilingüismo. En el extremo inferior y al centro ubicamos el "portuñol", más como un hecho situacional que como una variedad consolidada.

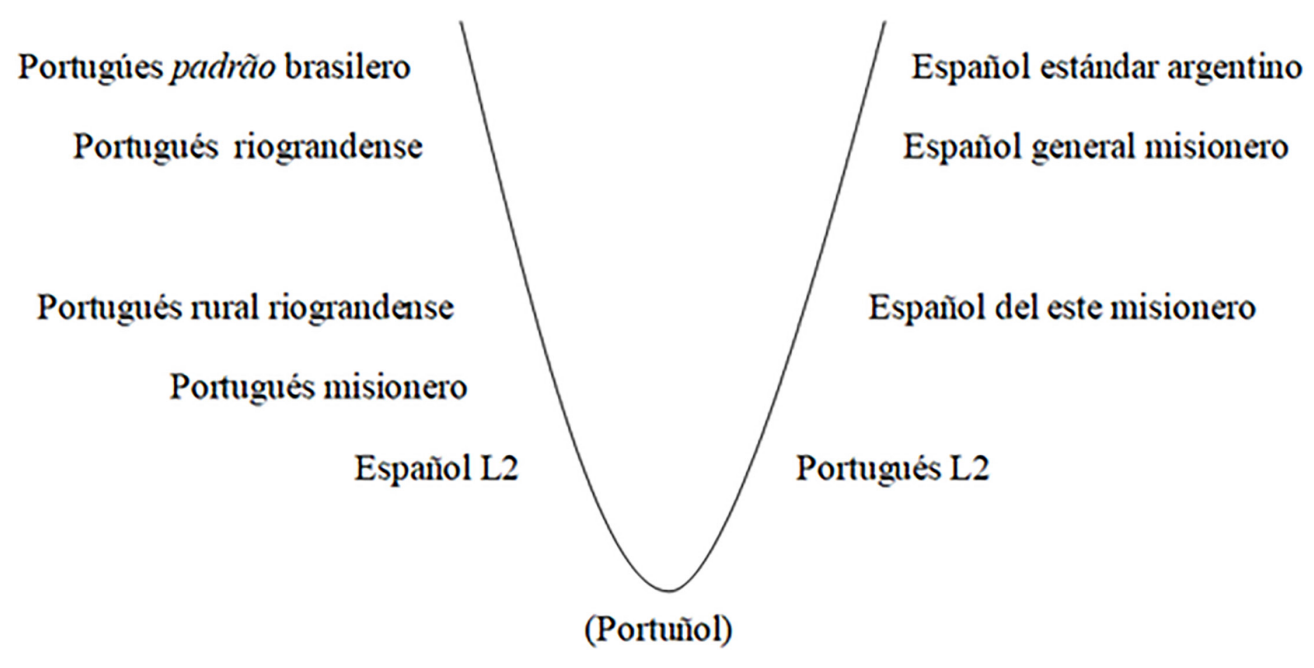

Tabla 1. Continuo de variedades iberorrománicas en la frontera este de Misiones

Estas variedades se adquieren y conocen de manera diferenciada en los sectores sociales de la comunidad, y su conocimiento depende del origen, situación social, y nivel de escolaridad de los hablantes. Describimos a continuación lo que nos parece son los grupos sociolingüísticos de la región de nuestra investigación, ubicándolos a su vez en un lugar del continuo.

2.Pues existe un uso un poco acrítico del término "portuñol” en el ambiente académico misionero y también en la lingüística dedicada al caso misionero. En otro estudio planteamos que el concepto de "portuñol” está más presente en el imaginario de la la sociedad inmediata envolvente que en los propios hablantes (quienes llaman "brasilero" a su variedad, cf. Cerno, 2019, p. 145-146). 


\section{Sectores sociolingüísticos}

Para ello nos servimos de dos categorías "emic": las de "brasileros" y "castellanos" (Cerno, 2019, p. 139; Clarissini da Maia y Méndez, 2018, p. 68). Junto a tales nociones debemos complementar la descripción de la comunidad hablante con dos categorías externas o "etic", necesarias para el modelo explicativo que ofreceremos. Se trata de las categorías de "brasileños" y "argentinos”, con las que nos referimos a los sectores externos a la comunidad, tendientes al monolingüismo y con un nivel de escolarización que favoreció la adquisición de la variedad estándar. En nuestro modelo, los "brasileños” residen del otro lado de la frontera, y los "argentinos" viven en pueblos o ciudades apartados de la influencia del portugués (Oberá, Posadas). Su competencia lingüística los ubica en el sector superior de la Tabla 1. Es interesante constatar que la voz "brasileros", ya un préstamo de la lengua lusa (port. brasileiro vs. esp. brasileño), se refiere en las comunidades estudiadas tanto a los ciudadanos del Brasil como a los descendientes de los inmigrantes brasileños que residen en las colonias, argentinos "en los papeles" pero con una identidad transnacional que el propio término indica: "Son gente que de un modo u otro son brasileros, venidos del Brasil ellos o sus padres. En el pueblo hablan normalmente portugués" (C.S., F, M, Piñalito). ${ }^{3}$

"Brasileros" es también la denominación que en algunas entrevistas surge para designar a personas de la colonia que emplean el portugués en la vida cotidiana, en el hogar, y con ciertos vecinos. Designa también a los inmigrantes del Brasil, bien la generación pionera (que sin embargo puede ser muy reciente), bien los descendientes ya nacidos en suelo argentino. Su origen extranjero y a la vez campesino los ubica como grupo en el ángulo inferior izquierdo del continuo de la Tabla 1, es decir más dominante de variedades locales y más alejado de las variedades estándar con difusión y prestigio. Las generaciones jóvenes crecen con bilingüismo doméstico español-portugués (siempre que los adultos también hablen español) y solo la escuela puede darles una aproximación al español general misionero y al estándar. El portugués padrão que escuchan a través de los mass media no parece tener demasiada influencia en su variedad nativa, salvo quizás en ciertos rasgos fonéticos, como la palatalización de /t/ $\mathrm{y} / \mathrm{d} /$ ante vocal alta, observado algunas veces sobre todo en mujeres.

“Castellanos" es la denominación eventual para familias que con poca o ninguna competencia de portugués. Una o dos generaciones atrás emigraron desde regiones castellano-hablantes del oeste y el sur de la provincia (o de Paraguay y Corrientes), y hablan la variedad de castellano que predomina en aquella zona, con una formación histórica a partir del sustrato guaraní pero que recibe actualmente más influencia del español general misionero y del español estándar. En la Tabla 1, los hablantes de este sector se ubican en el lado derecho y hacia el centro. El español del este misionero no forma parte de su competencia básica y más bien constituye, creemos, un recurso de estilo. Es también el sector que habla el portugués L2 en el sentido que lo definimos arriba. La escolarización de este grupo es por otra parte más exitosa que la de los "brasileros”.

3. Abreviaturas: C.S. $=$ iniciales del informante, $M=$ masculino, $F=$ femenino, $J=$ joven, $18-30$ años, $A=$ adulto, 35-55 años, $\mathrm{M}=$ mayor, +55 . En caso de diálogo: $\mathrm{INV}=$ investigador, $\mathrm{INF}=$ informante) . 
Los brasileños (o "brasileros brasileros", como dicen algunos para diferenciarlos de los "brasileros" locales) hablan un portugués general próximo al padrão, el portugués riograndense, con mayor proximidad a las modalidades procedentes de los centros de prestigio, como Rio de Janeiro y São Paulo. El conocimiento del castellano por parte de estos hablantes es pobre y se limita a las funciones básicas del intercambio comercial. Si bien el español suele ser materia en las escuelas brasileñas, y las actitudes sobre su utilidad no son siempre positivas. Por otra parte, el uso del español por parte de los brasileños es mucho menos frecuente que el de los argentinos que usan el portugués (Lipski 2018, p. 48; Kaufmann, 2009, p. 294).

\section{Usos, contextos y significaciones}

El uso de este repertorio sociolingüístico nos parece depender de un saber previo acerca del tipo de situación, de mayor o menor distancia social, y de lo que se sabe acerca del hablar habitual del/ los interlocutor/es en situaciones parecidas. En contextos de proximidad social existe una selección más libre de las lenguas y es posible que sean estos los ámbitos de uso fluido del code mixing, aunque no ha sido posible identificar hasta ahora patrones estables (Cerno 2019, p. 142). Por consiguiente lo que sigue se refiere a las situaciones con distancia social. Estas se definen a partir del poco conocimiento del interlocutor o poca intimidad, o bien por ubicarse dentro de la esfera institucional (escuelas, aduanas, policía) o por tratarse de actividades externas a la cultura local (la política, el comercio, el trabajo no rural). Presentamos aquí un modelo probable, basado en nuestras observaciones y entrevistas:

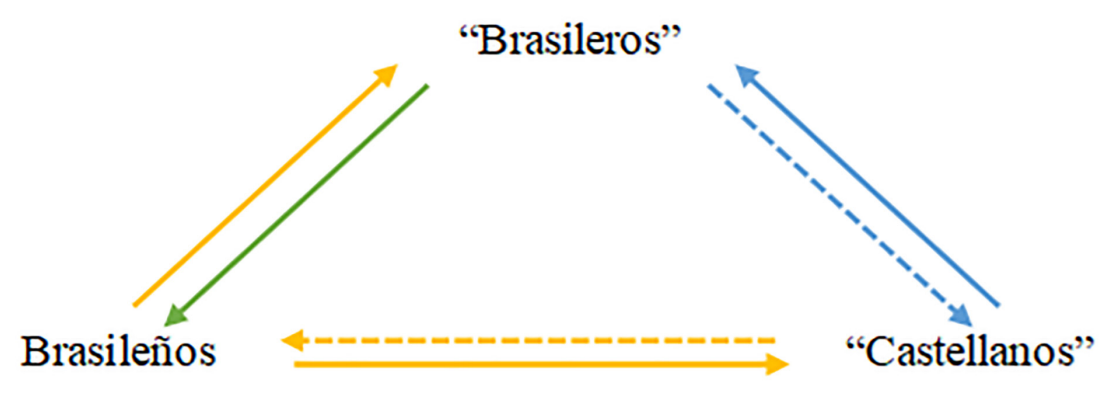

Tabla 2. Uso de las variedades lingüísticas en situaciones de distancia social

Las flechas, seis en total, intentan representar nuestra respuesta a la pregunta de "quién habla a quién en qué lengua” "Brasileros”, brasileños y “castellanos” simbolizan los grupos sociolingüísticos que comparten los espacios de interacción en la comunidad. Cada uno de estos tipos sociales dirige una flecha (el discurso) a los otros dos tipos y recibe una flecha de cada uno de ellos. La línea continua representa la lengua nativa, norma del grupo de pertenencia, y la línea de puntos la lengua del exogrupo, hablada como L2 por el hablante y normalmente con interferencia de su lengua primera. La flecha amarilla continua representa el portugués padrão riograndense, la azul continua el español general misionero, y la verde el portugués misionero. La flecha discontinua amarilla representa la variedad de portugués hablada como L2 por los nativos en español (“castellanos"), y la flecha discontinua azul representa al español hablado como L2 por los nativos en portugués misionero ("brasileros"). 
Nuestra explicación de estos fenómenos se apoya en el concepto de "acomodación lingüística" (Schepard, Giles y Le Poire, 2001; Coupland, 1995). El conocimiento previo de la situación crea una expectativa en función de la lengua que se elegirá para el intercambio. Se trata de un proceso mediado por los hábitos de la comunidad donde, si bien puede haber grados intermedios, existen básicamente dos posibilidades rígidas: la lealtad a la propia lengua/dialecto (maintenance) y la acomodación a la lengua/dialecto del interlocutor (accommodation). En los grados intermedios existe la posible convergencia entre las variedades en juego (en principio sólo de alcance situacional, aunque puede trasladarse al cambio lingüístico, cf. Auer y Hinskens, 2005). Dejando de lado, por razones de claridad, las posibilidades intermedias de convergencia, nuestro esquema de la Tabla 2 indica solo las situaciones de mantenimiento y de acomodación. De este modo, expresa que los hablantes de portugués misionero (los "brasileros") realizan habitualmente un acto de acomodación cuando hablan con los vecinos del sector "castellano", dejando de lado su lengua nativa para hablar la del interlocutor, y que lo mismo hacen por su parte los del sector "castellano" cuando identifican a alguien como brasileño. Haciendo abstracción de lenguas y variedades y quedándonos solo con el hecho de la acomodación y el mantenimiento, el esquema se ve de la siguiente manera.

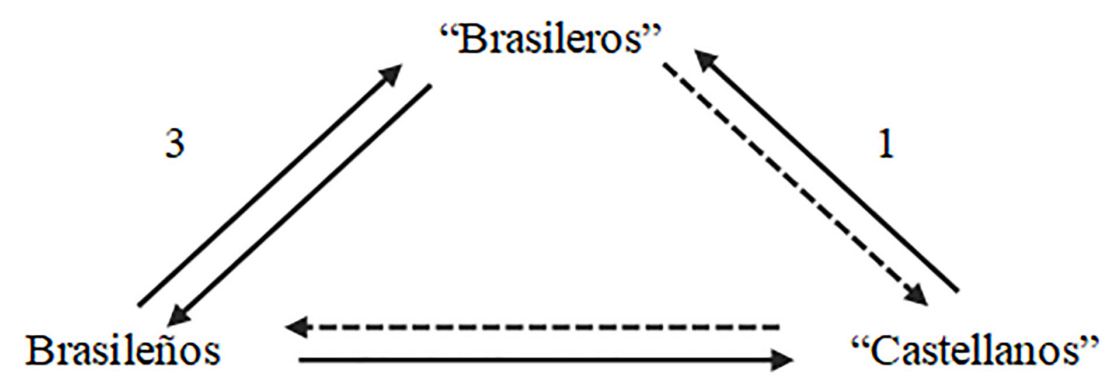

Tabla 3. Procesos de mantenimiento y acomodación lingüística

Se observa en la Tabla 3 que solo los ciudadanos brasileños mantienen su variedad en las diferentes situaciones de contacto. E1 mantenimiento de los “castellanos", por su parte, se practica solo en comunicación con los hablantes de portugués misionero (situación 1). En otro contexto (situación 2) los hablantes nativos de español se acomodan a los brasileños, empleando el portugués mejor o peor hablado que conocen (portugués L2). Los "brasileros", hasta donde sabemos, emplean su propia variedad en comunicación con los brasileños (situación 3). Estos útlimos, por su parte, identifican el portugués misionero como diastrato y lo consideran estigmatizante. El mantenimiento mutuo observado en (3) indicaría el poco interés en acomodarse al modelo del portugués padrão por parte de los inmigrantes. Por útlimo, la situación que se forma en (1) implica un tipo de acomodación asimétrica y unidireccional (lo mismo que la situación 2). Con todo es parecida a la situación (3) porque corresponde a una situación de contacto interdialectal, entre la variedad "alta" y variedades socialmente marcadas. La situación (2) es distinta porque no pone en juego un diastrato sino más bien una "interlengua" con función acotada al intercambio fronterizo. 


\section{O que significa falar. Significados sociales y usos del habla}

Las situaciones 1, 2 y 3 de la Tabla 2 conllevan a asociaciones, evaluaciones y reflexiones de distinto tipo por parte de una decena de nuestros informantes, si bien nuestros datos al momento son más ricos para el grupo "castellano". Con respecto a la situación (1), ya otros estudios indican que, para hablar con desconocidos, la lengua que elige el hablante de portugués misionero es el castellano (Lipski 2017, p. 400). Nuestro trabajo muestra que también esta es la opción si sabe que esa es la lengua del interlocutor.

nosotros ya sabemos dónde hablar castellano y dónde portugués. Porque hay algunos que yo conozco viste. Algunos de los que no conozco llego y ya hablo en castellano. (M.F., F,J, Piñalito)

No, con L... nunca hablé en portugués. Siempre en castellano, porque los hijos de él siempre en castellano también. Ellos tienen eso en la cultura de ellos. (E.R., F, A, Piñalito)

$I N V:$ ¿Y con un desconocido? ¿En qué idioma hablás? INF= En castellano. En castellano hasta ver un poco quién es. (Y.S., F, A, Piñalito)

La acomodación del código por parte de estos "brasileros" de Misiones, hasta donde sabemos, no parece conllevar sentimientos de conflicto, se trata de una práctica que se presta a "facilitar las cosas" (R.R., M.M, Piñalito). Con todo es preciso tener en cuenta las significaciones de prestigio que evoca el español general misionero frente al hablante de portugués misionero. M.G., político de San Antonio, explica su forma de hablar frente a los "brasileros" de Piñalito. Cuando le preguntamos qué idioma habla cuando va a visitar a "la gente humilde":

Uso el castellano, lo más preciso posible. Para mostrar que tengo conexión con allá [Posadas, Casa de Gobierno]. Pero por ahí meto alguna palabrita de portugués para mostrar que soy de acá. (M.G., M, A, San Antonio)

El valor indicial de las variedades, que enfrenta lo "local" a lo "regional" y permite movilizar la identidad social, como se expresa en esta declaración. Por otra parte, dada la situación transnacional de muchos de los migrantes brasileros, ligada a la ocupación de tierras, para algunos hablantes "castellanos", ser leales a la lengua nacional frente a los hablantes de portugués misionero significa un acto de "patriotismo" (cf. Cerno 2019). Con la misma lógica, la situación 2 es evaluada como negativa:

No sé porqué nosotros tenemos que ir allá [Brasil] y hablar castellano. Los brasileros [= brasileños] vienen acá y no hacen ni el esfuerzo de hablar algo de castellano aunque sea. (Y.S., F, A, Piñalito)

Nosotros nos dejamos dominar muy fácil la lengua, porque el brasilero [= brasileño] no te va a venir a hablar castellano... pero nosotros sí dejamos torcer la lengua, porque ellos hablan, en brasilero, y nosotros les hablamos en castellano, y él se hace del loco que no entiende... y ahí nosotros pum, [cambiamos] la lengua en brasilero. (J.L., M, M, Piñalito)

Le felicito [a unas chicas que no hablan en portugués con los brasileños]. Le felicito porque los brasileros [= brasileños] no dan brazo a torcer para nosotros. Ellos vienen acá y van a hablar brasilero y vas allá y ellos no te van a hablar castellano. [Ellos] son patriotas. Por eso les felicito a las nenas. Son patriotas ellas. (R.R., M.M, Piñalito) 
En el cercano pueblo de Comandante Andresito, A.S. trabaja atendiendo al público para una obra social. Ella es hablante de castellano como L1, y procede de Posadas. Vive hace 10 años en Andresito. En su descripción se pueden apreciar las diferencias que existen en el uso del repertorio de los “colonos" (que hablan portugués, situación 1) y los "brasileños” (situación 2).

INF: Generalmente la gente de las colonias entra a una tienda y habla portugués. Si vos les cortás el mambo y hablás castellano, ellos siguen en castellano, todo cruzado. Yo [a los colonos] no les hablo en portugués. No quiero entrar en ese portuñol porque después en Brasil no te entienden.

$I N V$ : Así que les cortás el mambo [= no cooperar].

INF: Yo les corto el mambo, porque sé que hablan castellano, sé que no son de Brasil. Pero si son brasileños sí, hago el esfuerzo. (A.S. F, A, Andresito)

La misma informante, con respecto a los “no colonos" de Andresito (que ella llama "argentinos"):

Los nativos de acá, argentinos, entienden y hablan portugués. Ellos usan el portugués para hablar en las tiendas [cuando van de compras a Brasil] [...]. El de Andresito [= "argentinos"] entra a una tienda [en Andresito] y te habla castellano.

\section{Conclusiones}

Con lo expuesto hasta aquí resulta que el portugués es la lengua más extensa en cuanto a sus dominios funcionales posibles, y la que más se mantiene en una escala hipotética de acomodación lingüística.
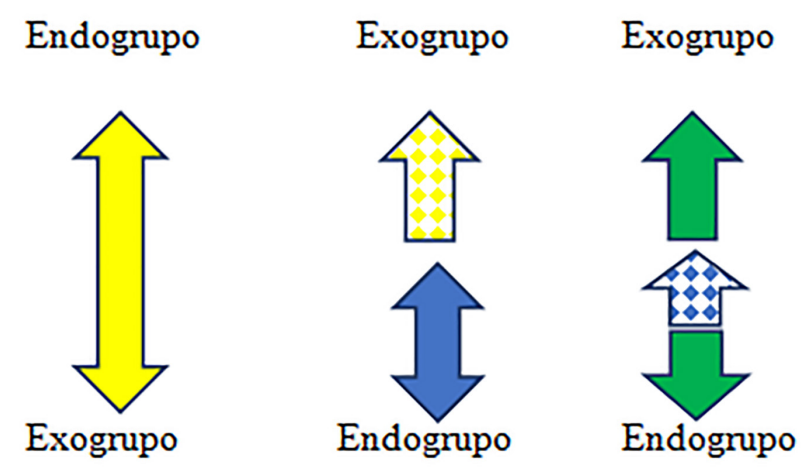

Brasil

Argentina

Tabla 4. Variedades, extensión funcional y reglas de acomodación lingüísticas

En la Tabla 4 se observa que la flecha amarilla doble, el portugués, alcanza el dominio de los otros grupos hablantes y funciona como lengua del intercambio en todos ellos. El castellano (general misionero y del este misionero), representado con azul, posee una extensión menor pues se usa solo en el interior de la comunidad nacional y, en ella, además de con el endogrupo, con la comunidad portuguésmisionero nativa. El portugués misionero (verde) se extiende por su parte sobre un dominio menor que el castellano, el del endogrupo, pero también se proyecta hacia el exogrupo en la comunicación con brasileños, consiguiendo en este sentido un alcance tan extenso como el español, si bien una parte del 
uso se concreta del otro lado de la frontera. Destacamos que la extensión funcional del castellano sobre el portugués misionero en Misiones no significa necesariamente mayoría de hablantes. En realidad, los hablantes nativos del portugués misionero suelen ser mayoría en las colonias del Alto Uruguay. El relegamiento de la lengua propia ante los hablantes de español constituye una forma de diglosia, motivada por la situación oficial del español en Misiones, y no por una subordinación numérica.

Entre el portugués y el español se crea por su parte una distribución funcional complementaria, que significa que el primero asume en el contexto de la frontera (también del lado argentino) la cualidad de "lengua vehicular", y el español se delimita al uso interno de la propia comunidad hablante, hecho que se explica por la percepción de superioridad económica y cultural que tienen los argentinos que residen en la frontera acerca del país vecino (cf. Kaufmann, 2009).

Nótese también que la flecha azul incluye potencialmente dos variedades del español, el castellano del este misionero y el castellano general misionero. El esquema simboliza así que ambas variedades se superponen en ese ámbito social, configurando una posible convergencia. Es también el contexto de ocurrencia del "portuñol" misionero, fenómeno con gran variación situacional e individual. Por su parte las flechas cuadriculadas muestran las variedades de L2 que se emplean para la acomodación lingüística, y se diferencian de las flechas plenas por hablarse con interferencias de la lengua nativa. La flecha azul cuadriculada es el castellano hablado por los nativos del portugués misionero, y la amarilla cuadriculada el portugués hablado por los nativos del castellano misionero, que como hemos visto corresponden a dos fenómenos distintos desde el punto de vista lingüístico y social. Es también interesante notar que el castellano como L2 comparte su ámbito funcional con las otras dos variedades de español representadas con el azul pleno.

\section{Referencias bibliográficas}

Abadía de Quant, I. (1996). Guaraní y español. Dos lenguas en contacto en el Nordeste argentino. Signo Ẽ Seña, 6, 197-233.

Altenhofen, C., Steffen, J. y Thun, H. (2018). Cartas de imigrantes de fala alemã. Pontes do papel dos bunsriqueanos no Brasil. São Leopoldo, Oikos.

Altenhofen, C. y Thun, H. (2016). As migrações e os contatos linguísticos na geografia linguística do sul do Brasil e Bacia do Prata. En De Andrade Aguilera, V. y Pereira Romano, V. (eds.), $A$ geolinguistica no Brasil: caminhos percorridos, horizontes alcançados (pp. 371-392). Londrina, Eduel.

Altenhofen, C. y Klassmann, M. (orgs.) (2011). Atlas Lingüístico-Etnográfico da Região Sul do Brasil (ALERS): Cartas Semântico-Lexicais. Porto Alegre, UFRGS/ Florianópolis, UFSC.

Amable, H. (1975). Las figuras del habla misionera. Santa Fe, Colmegna.

Auer, P. y Hinskens, F. (2005). The role of interpersonal accommodation in a theory of language change. En Auer, P., Hinskens, F. y Kerswill, P. (eds.), Dialect Change. Convergence and Divergence in European Languages (pp. 335-376). Nueva York, Cambridge University Press. 
Camblong, A. (2014). Habitar las fronteras. Posadas, EDUNAM.

Coupland, N. (1995). Accommodation Theorie. En Verschueren, J., Ostman, J-O y Bloomaert, J. (eds.), Handbook of Pragmatics (pp. 21-26). Amsterdam, John Benjamin.

Cerno, L. (2019). Portugués, español, alemán y brasilero. Lenguas y variedades en contacto en el Alto Uruguay (Misiones, Argentina). Avá. Revista de Antropología, 34, 131-153.

Cerno, L.; Gutiérrez Maté, M. y Steffen, J. [En prensa]. Tener existencial en variedades hispánicas, con especial atención a criollos y al español de Misiones. En Palacios, A. y Sánchez Paraíso, M. (eds.), Dinámicas lingüísticas de las situaciones de contacto. Berlin/New Work, De Gruyter.

Clarissini da Maia, I. y Méndez, S. C. (2018). Historia, entramados y cruces de la cultura fronteriza: efectos en los discursos. La Rivada, 6 (10), 59-74. http://bit.ly/30wjdPG

Daviña, L. (2003). Fronteras discursivas en una región plurilingüe. Español y portugués en Misiones (Tesis de maestría inédita). Universidad de Buenos Aires.

Gallero, C. (2016). Las peripecias del viaje y la historia oral en el estudio de la inmigración alemanabrasileña en Misiones, Argentina. História Oral. Associação Brasileira de historia oral, 19 (1), 163-191.

Gallero, C.y Kraustofl, E. (2009). Proceso de poblamiento y migraciones en la Provincia de Misiones, Argentina (1881-1970). Avá. Revista de Antropología, 16, 245-264.

Grünwald, G. K. (1977). Diccionario etimológico lingüistico de Misiones. Posadas, Puente.

Kaufmann, G. (2009). Falar Espanhol or Hablar Portugués. Attitudes and Linguistic Behavior on the Brazilian-Uruguayan and Brazilian-Argentinian Borders. Romanistisches Jabrbuch, 60, 276-317.

Lipski, J. (2015). Portuguese/portuñol in Misiones, Argentina: another "Fronterizo"? En Sessarego, S. y González-Rivera, M. (eds.), New perspectives on Hispanic contact linguistics in the Americas (pp. 253-281). Frankfurt / Madrid, Vervuert / Iberoamericana.

Lipski, J. (2017a). Portuguese or Portuñol? Language contact in Misiones, Argentina. Journal of Linguistic Geography, 4, 47-64.

Lipski, J. (2017b). La evolución de la interfaz portugués-español en el noreste argentino. En Corbella, D. y Fajardo, A. (eds.), Español y portugués en contacto. Préstamos léxicos e interferencias (pp. 391-412). Berlín / Boston, De Groyter.

Lipski, J. (2018). La interfaz portugués-castellano en Misiones, Argentina: zona de prueba para la alternancia de lenguas. Estudios Filológicos, 60, 169-190.

Putnam,M.T.y Lipski,J.(2016). Null arguments in transitional trilingual grammars: Field observations from Misionero German. Multilingua, 35 (1), 85-104.

Schepard, C. A.; Giles, H. y Le Poire, B. A. (2001). Communication Accommodation Theory. En Robinson, P. W. y Giles, H. The New Handbook of Language and Social Psychology (pp. 33-56). Chichester / New York, John Wiley \& Sons. 
Schiavoni, G. (1998/1999). Porto capivara. Los ocupantes agrícolas de la frontera argentino-brasileña (Misiones, Argentina). Estudios migratorios latinoamericanos, 40-41, 13/14, 449-469.

Steffen, M. (2021). Acá no hay español nem português, é portunhol. El español en contacto con el portugués en Misiones (Argentina). En Blestel, E. y Palacios, A. (eds.), Variedades del español en contacto con otras lenguas (pp. 131-155). Berlín, Peter Lang.

*Leonardo Cerno es Investigador adjunto en elInstituto de Estudios Sociales y Humanos (CONICETUNaM, Posadas). Licenciado en Letras (2000, dir. Yolanda Ayala). Becario en el Instituto de Letras de la Facultad de Humanidades de la UNNE (1996-97, dir. Aldo Valesini; 1998-2001, dir. Marta S. López), y en el IIGHI-CONICET (2003-2008, dir. Marisa Censabella). Doctor en Humanidades y Artes - Lingüística (UNR, 2011, dir. Wolf Dietrich).

RECIBIDO: 20/11/2020

ACEPTADO: 20/12/2020 